\title{
Locus of Control and Health Promotion for Marginalized Populations
}

\author{
Cara Stephenson-Hunter \\ Albert Einstein College of Medicine-Montefiore Medical Center, Bronx, New York \\ Kathryn Dardeck \\ Walden University
}

\begin{abstract}
Socioeconomic health disparities in the United States have remained largely unchanged for decades. This remains the case even for preventable illness and disease. Current health behavior theories and interventions rely on the perception of control over one's fate to achieve desired behavior. In low-income and other marginalized populations, however, hopelessness and the perception of having limited control may make interventions less effective. The purpose of this quantitative study was to examine the role of the locus of control (LOC) as defined by the degree to which one believes outcomes are determined by external forces such as chance or authority figures as an adaptive response to poverty. Using cross-sectional survey methodology, 136 U.S. adult participants were recruited through snowball sampling to anonymously complete measures of the Multidimensional Locus of Control, the Health-Promoting Lifestyle Profile II, the Kessler Psychological Distress Scale, and a demographic questionnaire. Hierarchical regression and bivariate analyses were used to test the hypotheses. Study results found that chance LOC mediated the relationship between socioeconomics and health lifestyles, while it was as associated with less healthy lifestyle choices than external authority figures (powerful others). Internal LOC was not found to provide any psychological protection from anxiety and depression for low socioeconomic populations. Recommendations included the need for additional studies to understand the role of LOC as it relates to health beliefs, behavior, and psychological wellbeing of marginalized populations.
\end{abstract}

Keywords: health disparities, locus of control, marginalized populations, socioeconomic status, health behavior, health-promoting lifestyles, health promotion

\section{Introduction}

Despite decades of public health interventions aimed at eliminating socioeconomic status (SES) health disparities in the United States, gradient health disparities between the low-, middle-, and high-SES populations remain (Chetty et al., 2016; Cooper et al., 2018). In fact, interventions based on the dominant health behavior models have successfully improved the health of affluent populations, thereby increasing the health gap between low and higher SES populations (Arcaya \& Figueroa, 2017; Goldberg, 2012). While physical environment, genetic predispositions, and access to care contribute to the increased morbidity and mortality in lower SES populations, health behavior accounts for a significant amount of illness and premature death, and follows the same SES gradient (Centers for Disease Control and Prevention, 2015; Havranek, et al., 2015).

This manuscript was completed in partial fulfillment of the doctoral requirements in health psychology at Walden University, Minneapolis, Minnesota, under the direction of Jay Dill, PhD, and Kathryn Dardeck, EdD.

Thank you to Ms. Alva Rodriguez for her editorial assistance in this process. 
The current approaches to health behavior change are heavily reliant on personal agency and the belief that outcomes are a consequence of one's own behavior, defined as an internal locus of control (LOC; Goldberg, 2012; Rotter, 1966). However, it is well documented that for people with low SES, events and circumstances are largely perceived as being controlled by fate, destiny, chance or powerful others (authority figures) defined as an external LOC (Adler, 2015; Angelova, 2016; Culpin, Stapinski, Miles, Araya, \& Joinson, 2015; Rotter, 1966). What has not been examined is the influence of low SES on global perceptions of control and interventions that can increase healthy behavior in populations with external control beliefs. While an internal LOC is considered optimal for physical health and numerous nonhealth related outcomes, an external LOC is psychologically compatible with and more prevalent in low-SES populations (Angelova, 2016; Rotter, 1966; Sheffer et al., 2012). Within external LOC, little is known about how beliefs of chance or powerful others differ in their relationship to health and health behavior. It is also unknown if having an internal LOC in low-SES conditions increases the risk of psychological distress.

The present quantitative study was intended to determine whether LOC is a mediator in the relationship between SES and health-promoting lifestyles (HPL), and if within external LOC domains, powerful others or chance are associated with fewer HPL factors. Further, this study intended to determine if an internal LOC orientation is associated with increased psychological distress. Although, previous studies compared health locus of control (HLOC; Wallston, Wallston \& DeVellis, 1978) to health behavior, to our knowledge there are no studies on the relationship between SES, general LOC, and HPL to assess whether poverty predicts overall or general LOC orientation (Aharon, Nehama, Rishpon \& Baron-Epel, 2018; Bennett, Goldstein, Gathright, Hughes, \& Latner, 2017; Grotz, Hapke, Lampert \& Baumeister, 2011). As well, we are unaware of any studies that examined whether an external LOC is psychologically protective for those living in poverty. Additionally, subdomains within external LOC (chance/powerful others) and their associated health risks and benefits for those living in poverty have yet to be determined. Examining the relationship between poverty and health-promoting behavior, as well as the role of LOC, may help to identify barriers to the adaptation of healthy lifestyles. It may also inform health interventions in low-SES communities, as well as contribute to a fundamental understanding of the relationships between SES, LOC, and health behavior.

\section{Literature Review}

Rotter's (1966) LOC theory explains how one makes sense of both positive and negative events based on beliefs about these events being caused by one's behavior or actions (internal), or people or forces outside of oneself (external). Levenson (1974) made a distinction within the domain of external LOC to differentiate between the belief that powerful others (authority figures) or chance exerted the most control over one's life. LOC is an extension of Albert Bandura's (1965) social cognitive theory, which explains how expectancies are learned and reinforced through our own experiences and observations of others' experiences. Socially disempowered individuals are more likely to be external in orientation and believe their efforts will be futile (Ahlin \& Antunes, 2015; Angelova, 2016; Nettle, 2010; Rotter, 1966). An external LOC may be adaptive and psychologically beneficial for those in low social positions (Bandura, 1965; Miller, Yu, Chem \& Brody, 2015). Similarly, learned helplessness explains why individuals succumb to seemingly uncontrollable negative conditions as a form of passive coping, such as the largely inescapable, adverse conditions associated with poverty (Seligman \& Maier, 1967). These beliefs may decrease motivation and persistence across many life domains, including health-promoting behavior.

Both poverty and external LOC are associated with poorer mental and physical health, higher risky health behavior, and fewer health protective and restorative behaviors (Cobb-Clark, Kassenboehmer, \& Schurer, 2014; Nettle, 2010). Behavior such as smoking, high consumption of fats and sugar, 
nonadherence to medical regimens, and health-screening avoidance continues to increase the risk of illness and premature death in this already vulnerable population (Cobb-Clark et al., 2014; Moy, Garcia, Bastian, Rossen \& Ingram, 2017). Low SES and poverty are believed to create a perception of powerlessness and decrease one's motivation to prevent negative events or circumstances (Adler, 2015; Angelova, 2016). Low SES during childhood often creates a time full of uncertainty and adversity, which has been shown to effect the persistence needed to sustain a health behavior change such as exercise or smoking cessation (Braveman, Cubbin, Egerter, Williams, \& Pamuk, 2010; Mittal \& Griskevicius, 2014; Turiano, Silva, McDonald, \& Hill, 2017). Sheffer et al. (2012) found that low SES, external HLOC, and cognitive impulsivity were coexisting factors that prevented smoking cessation efforts. While awareness of the social determinants of health has shifted the public health focus from medical care to social factors influencing health such as the built environment, education, and social support, this awareness has failed to translate into health promotion practices that address SES health disparities (Centers for Disease Control and Prevention, 2015; Healthypeople.gov, 2015).

\section{Dominant Health Promotion Models}

The most salient health behavior theories are the health belief model (Hochbaum, 1960) the transtheoretical model (Prochaska \& DiClemente, 1983), the theory of planned behavior (Ajzen, 1985), and the health promotion model (Pender, 1996) The health belief model, transtheoretical model, theory of planned behavior, and health promotion model are rational-choice models that consider individuals as rational agents of their own health and require perception of control as a prerequisite to health behavior change (Goldberg, 2012). While self-efficacy is one facet of social cognitive theory used in the transtheoretical model and theory of planned behavior, it refers to the belief in one's ability to control a behavior, not the belief in one's ability to control an outcome (Ajzen, 1985; Prochaska \& DiClemente, 1983). LOC refers to the belief that negative outcomes and consequences can be reduced or avoided through one's actions (Rotter, 1966). Researchers found that weight-loss interventions that focused on personal responsibility influenced weight loss for internals but were ineffective and influenced negative self-thoughts and counterarguments for externals (Holt, Clark, Kreuter, \& Scharff, 2000). Effective interventions for persons with external LOC may be those that address the underlying perception of control before addressing specific health behavior.

\section{Method}

\section{Participants and Procedure}

Upon approval by the university's Institutional Review Board (Approval Number 30-31-17-0111465), 167 participants were recruited by snowball sampling to participate in the study and complete either an electronic or paper survey. Electronic surveys were used to facilitate wide dissemination. Paper surveys were administered to gain a representative sample, including those who were not computer literate and those without computer access. Inclusion criteria were (a) being at least 18 years of age, (b) residing within the United States, and (c) understanding and reading English. Participants were informed of their rights to discontinue participation in the research study at any time and were assured that information obtained would be kept anonymous. Participants were also provided with mental health resources and crisis hotline contact information.

The survey contained SES and demographic questions, the Multidimensional Locus of Control, the Health-Promoting Lifestyle Profile II, and the Kessler Psychological Distress Scale (KP10). Participants for online surveys were recruited through email and Facebook advertisements posted by the researcher and the researcher's colleagues. These advertisements included a link to a SurveyMonkey page containing the study details, inclusion requirements, and informed consent. 
Paper surveys were administered in person in public areas throughout the New York, New York, metropolitan area on five occasions between April 1 and May 31, 2017. Study details and an informed consent document were administered to all who expressed interest in participating. Data collected from paper surveys were anonymous; data collected from online surveys recorded the IP addresses of respondents to prevent participants from completing multiple surveys. Participants' IP addresses were removed for data export from SurveyMonkey, and each participant was assigned a unique subject identification number. The data collection phase lasted for 60 days.

\section{Measures}

SES was measured by calculating percentage of federal poverty level (FPL) based on 2017 poverty guidelines outlined by the U.S Department of Health and Human Services (2017). Self-reported annual combined family income and number of children and adults in the household were used to calculate household income, which was matched to the federal poverty threshold according to household size (U.S Department of Health and Human Services, 2017). The formula used to calculate the percentage of federal poverty guideline was income divided by U.S. federal poverty guidelines for household size. Therefore, to calculate the FPL for two adults and three children with a combined family income of $\$ 30,000$, one would divide the income by the 2017 poverty threshold for a family of two adults and three children $(\$ 20,780)$ for the outcome of 1.44 , or $144 \%$ of the FPL (U.S Department of Health and Human Services, 2017).

LOC was measured using the 24-item Multidimensional Locus of Control Scale (MLOC; Levenson, 1974). The MLOC contains 24 questions, eight for each of the three subscales: Internal (MLOC-I), Powerful Others (MLOC-PO), and Chance (MLOC-C). A 0-6 Likert scale was employed for participants to indicate their responses to items such as "Whether or not I get to be a leader depends mostly on my ability," "I feel like what happens in my life is mostly determined by powerful people," and "To a great extent, my life is controlled by accidental happenings." The range of scores for each of the three domains is between 0 and 48. A respondents' scores could be 12 on MLOC-I, 24 on MLOC-PO, and 48 on MLOC-C, indicating a high belief in chance. Cronbach's alphas were 64, .74, and .78 , respectively.

HPL was measured using the Health-Promoting Lifestyle Profile II (Walker, Sechrist, \& Pender, 1995), which measures the frequency of self-reported health-promoting behavior using 52 questions covering six domains: Health Responsibility, Physical Activity, Nutrition, Spiritual Growth, Interpersonal Relations, and Stress Management. Participants indicate how often they "discuss health concerns with health professionals," "follow a planned exercise program," "limit use of sugars and food containing sugar," "spend time with close friends," and "take some time for relaxation each day" using a 4-point scale ranging from never to routinely. Total HPL scores range between 1 and 4 and Cronbach's alpha was .94.

Psychological distress was measured using the KP10 (Kessler, 2002), a 10-question self-report inventory of affective symptoms within the last 30 days. The KP10 measured how often during the past month participants felt "tired out for no good reason," "nervous," "so nervous that nothing could calm you down," "hopeless," "restless or fidgety," "so restless you could not sit still," "sad or depressed," "that everything was an effort," "so sad that nothing could cheer you up," and "worthless." The range of possible scores is between 10 and 50 , with scores of $\geq 30$ indicating higher levels of psychological distress and increased risk of anxiety/depression. Cronbach's alpha was .88.

Additional demographic information collected included educational attainment, occupation, home ownership category, sex, and race/ethnicity. SPSS Version 21 was used for all analyses including a hierarchical multiple regression to determine if MLOC mediated the relationship between SES and HPL (Baron \& Kenny, 1986). Bivariate analyses were conducted to determine differences in the 
direction and strength of the relationship between MLOC-C, MLOC-PO, and HPL as well as to examine the relationship between MLOC-I orientation and psychological distress for low-SES populations. Frequencies and Pearson correlations were used for descriptive statistics.

\section{Results}

Participants who did not provide responses on the MLOC, HPL, KP10, and/or SES pages of the survey were excluded from the study, resulting in a final sample size of 136 . Table 1 displays participant characteristics. More than half of the respondents were female, and $108(78 \%)$ reported an annual income between $\$ 75,000$ and $\$ 100,000$.

Table 1. Frequencies: Demographics ( $\mathrm{N}=136)$

\begin{tabular}{|c|c|c|}
\hline Demographic & $N$ & $\%$ \\
\hline Female & 110 & $81 \%$ \\
\hline \multicolumn{3}{|l|}{ Age } \\
\hline $18-34$ & 37 & $27 \%$ \\
\hline $35-54$ & 77 & $57 \%$ \\
\hline$\geq 55$ & 22 & $16 \%$ \\
\hline \multicolumn{3}{|l|}{ Race/Ethnicity $(n=135)$} \\
\hline Asian/Pacific Islander & 4 & $3 \%$ \\
\hline Black/African American & 63 & $47 \%$ \\
\hline Hispanic/Latino & 26 & $19 \%$ \\
\hline White & 31 & $23 \%$ \\
\hline Mixed/Other & 11 & $8 \%$ \\
\hline \multicolumn{3}{|l|}{ Combined family income } \\
\hline$\$ 5,000-\$ 24,999$ & 12 & $9 \%$ \\
\hline$\$ 25,000-\$ 49,999$ & 19 & $14 \%$ \\
\hline$\$ 75,000-\$ 99,999$ & 47 & $35 \%$ \\
\hline$\geq \$ 100,000$ & 58 & $43 \%$ \\
\hline \multicolumn{3}{|l|}{$\begin{array}{l}\text { Highest educational level } \\
\text { achieved }\end{array}$} \\
\hline High school diploma/GED & 25 & $18 \%$ \\
\hline Associate's degree & 19 & $24 \%$ \\
\hline Bachelor's degree & 33 & $13 \%$ \\
\hline Graduate degree & 58 & $43 \%$ \\
\hline
\end{tabular}

Note: Age and Combined Income categories collapsed; age was categorical in increments of 5 years.

A correlation analysis and descriptive statistics of the study variables revealed significant relationships between all LOC domains, HPL, and KP scores at $p<.001$, for this study sample (see Table 2). Both external domains shared a significant relationship with SES at $p<.001$ for chance and $p<.002$ for powerful others.

\section{Preliminary Analyses}

Tests of normality, linearity, multicollinearity, and homoscedasticity were conducted before proceeding with the mediational analysis. Results indicated that the standardized residuals were normal, as the histogram followed the bell shaped curve. The plots of the standardized predicted values and the standardized residuals revealed no violation of linearity or homoscedasticity. While a variable inflation factor $\geq 10$ indicates multicollinearity, the variable inflation factors for the predictors were all $<2$, indicating that there was no violation of multicollinearity. 
Table 2. Descriptive Statistics and Pearson's Correlations Between Variables ( $\mathrm{N}=136)$

\begin{tabular}{|c|c|c|c|c|c|c|c|c|c|}
\hline Variable & $M$ & $S D$ & Range & 1 & 2 & 3 & 4 & 5 & 6 \\
\hline 1. Internal & 33.1 & 6.24 & $13-42$ & - & & & & & \\
\hline 2. Chance & 16.4 & 6.97 & $1-33$ & .02 & - & & & & \\
\hline 3. Powerful others & 16.4 & 7.26 & $2-41$ & .02 & $.53^{* * *}$ & - & & & \\
\hline $\begin{array}{l}\text { 4. Health promoting } \\
\text { lifestyles }\end{array}$ & 2.6 & .42 & $1.4-3.5$ & $.29^{* * *}$ & $-.41^{* * * *}$ & $-.23^{* *}$ & - & & \\
\hline 5. Psychological distress & 20 & 7.53 & $10-46$ & $-.23^{* * *}$ & $.34^{* * *}$ & $.33^{* * *}$ & $.51^{* * *}$ & - & \\
\hline 6. Socioeconomic status $\mathrm{s}^{\mathrm{a}}$ & $357 \%$ & 191.6 & $15-826 \%$ & -.04 & $-.35^{* * * *}$ & $-.19^{*}$ & $.27^{* *}$ & $-.19^{*}$ & - \\
\hline
\end{tabular}

a Percentage of distance from federal poverty line.

${ }^{*} p<.05 .{ }^{* *} p<.01$. ${ }^{* * *} p<.001$ (one-tailed).

The following relationships must be established to test mediation: (a) predictor and criterion, (b) mediator and predictor, (c) mediator and criterion (Baron \& Kenny, 1986). Because no significant relationship existed between MLOC-I and SES $(\beta=-.124, p=.151)$ or MLOC-PO and SES $(\beta=-.091$, $p=.290)$, MLOC-I and MLOC-PO were dropped from the path analysis. There was a significant relationship between MLOC-C and SES $(\beta=-.319 p<.001)$ and MLOC-C and HPL $(\beta=-.412, p<$ $.001)$; therefore, MLOC-C was analyzed as the sole mediator in the model.

\section{Does LOC Mediate the Relationship Between SES and HPL?}

A hierarchical multiple regression was performed by entering demographic and predictor variables in blocks as determined by the research hypothesis. Results of the multiple regression indicated that Block 1 (demographics combined) was a significant predictor of HPL, $F(3,131)=5.661, p<.001$, whereas age, sex, and race/ethnicity predicted $11.5 \%\left(r^{2}=.115\right)$ of the variability in HPL scores (see Table 3). In Block 2 of the regression model, MLOC-C accounted for $13 \%\left(r^{2}=.245\right)$ of the variance in HPL scores, above the predictors in Block $1, F(1,130)=22.418, p<.001$. For Block 3, SES only accounted for $1 \%\left(r^{2}=.253\right)$ of the variance in HPL scores, above the demographic variables and MLOC-C, $F(1,129)=1.420, p=.236$. SES failed to make a significant contribution to the regression model $(\beta=.097, p=.236)$ and was not a significant predictor of HPL scores when MLOC-C was included in the model. Therefore, MLOC-C served as a mediator in the relationship between SES and HPL.

Table 3. Summary of Hierarchical Regression Analysis for Variables Predicting Health Promoting Lifestyles $(\mathrm{N}=136)$

\begin{tabular}{lccccccccc}
\hline & \multicolumn{3}{c}{ Block 1 } & \multicolumn{3}{c}{ Block 2 } & \multicolumn{3}{c}{ Block 3 } \\
\cline { 2 - 9 } Variable & $\boldsymbol{B}$ & $\boldsymbol{S E} \boldsymbol{B}$ & $\boldsymbol{\beta}$ & $\boldsymbol{B}$ & $\boldsymbol{S E} \boldsymbol{B}$ & $\mathbf{B}$ & $\boldsymbol{B}$ & $\boldsymbol{S} \boldsymbol{E} \boldsymbol{B}$ & $\mathbf{B}$ \\
\hline Sex & .082 & .086 & .078 & .113 & .080 & .108 & .105 & .081 & .100 \\
Age & .115 & .029 & $.332^{* * *}$ & .070 & $.070^{*}$ & .028 & .068 & .028 & .194 \\
Race/Ethnicity & -.005 & .031 & -.013 & -.019 & -.024 & -.029 & -.021 & .029 & -.057 \\
MLOC-C & & & & -.023 & .005 & $-.389^{* *}$ & -.021 & .005 & $-.357^{* *}$ \\
SES & & & & & & & .000 & .000 & .097 \\
$R^{2}$ & & .115 & & & .245 & & & .253 & \\
$\Delta R^{2}$ & & & & & .130 & & & .008 & \\
$F$ for $\Delta R^{2}$ & & $5.66^{* *}$ & & & $22.41^{* *}$ & & & 1.42 & \\
\hline
\end{tabular}

Note. MLOC-C = Multidimensional Locus of Control Scale-Chance subscale; SES $=$ socioeconomic status.

${ }^{*} p<.05 .{ }^{* *} p<.01$. 


\section{Differences in Health Behavior Between External Subdomains}

To test the strength and direction of the relationship between the external domains of MLOC-PO and MLOC-C and HPL, a Pearson correlation analysis was conducted including the HPL scores and the MLOC-PO and MLOC-C variables. The Pearson correlation coefficient for the total HPL score with the MLOC-C score, $r(135)=-41, p<.001$ (one-tailed), was stronger and more significant than the HPL and the MLOC-PO score, $r(135)=-23, p=.008$ (one-tailed). Meng's $z$ test for comparing correlations (Meng, Rosenthal, \& Rubin, 1992) was performed to determine if the correlations between MLOC-C scores and HPL were significantly different than the correlation between MLOCPO and HPL. The difference between these correlations was statistically significant, $z=2.364$, $p<.01 ;$ therefore, the second hypothesis was supported.

\section{Is an Internal LOC Associated With Higher Psychological Distress in Low SES?}

The relationships between MLOC-I, SES, and KP10 were analyzed using Pearson correlations. The median for the SES variable was obtained using descriptive statistics and used to split the variable into two categories, coded dichotomously to indicate high (at or above the median) and low (below the median) SES categories. The median SES, as measured by percentage of FPL, was $312 \%$. The lowSES group included participants with FPL $<310 \%(n=63)$ and the high-SES group included those with FPL of $\geq 311 \%$ ( $n=73$ ) A one-tailed Pearson correlation analysis was conducted with MLOC-I score and the KP10 score for the high- and low-SES groups. Higher scores on the KP10 are associated with more psychological distress symptoms. The results indicated that for the low-SES group, MLOC-I shared an inverse relationship with KP10 scores, $r(62)=-.22, p=.04$, whereas for higher SES, LOC- I was also negatively correlated with KP10 scores, $r(72)=-.27, p=.01$. However, the negative correlation between MLOC-I and psychological distress (KP10) was stronger and more significant for the higher SES group. The predicted relationship between MLOC-I, SES, and KP10 was not supported.

\section{Discussion}

The present study demonstrates the role of general chance LOC orientation as a mediator in the relationship between SES and health beliefs and behavior, thus illustrating how general control expectancies predict outcomes across all life domains, including health. The implications are that those who perceive most life circumstances to be controlled by luck may be less likely to engage in healthy behavior. According to Proffitt Leyva and Hill (2018), numerous adverse experiences and a lack of stability in one's environment during childhood lead to the development of an unpredictability schema, hindering self-regulatory behavior in adulthood, including those related to health behavior.

Findings related to HPL for MLOC-C and MLOC-PO orientations indicate that the MLOC-C orientation is associated with fewer health-promoting behaviors than MLOC-PO. Therefore, within externality, there are differences in health risks between the domains. The prediction that MLOC-I would be associated with negative psychological symptoms for low-SES groups was not confirmed. The results revealed that internality was associated with lower psychological distress for high- and low-SES groups. Thus, while an external LOC may form in response to an unresponsive environment, it might not be psychologically protective. Elliot, Turiano, Infurna, Lachman, and Chapman (2018) found that perceived control was associated with increased resilience in adverse conditions. It buffered the mortality risk associated with cumulative stress exposure and improved recovery from trauma through greater coping self-efficacy. 


\section{Limitations}

The findings of this study must be considered within the context of its limitations. Conveniencesampling methods were used and therefore the study sample was not representative of the demographics of the general population. This small sample size provided adequate power for the statistical analyses (Faul, Erdfelder, Lang \& Buckner, 2007), but the lack of diversity in the participants was an additional limitation. There was an overrepresentation of high-SES participants, and the majority of the sample was from the New York area. Most of this study's participants had higher MLOC-I scores relative to the MLOC-PO and MLOC-C scores. A crosssectional method also did not allow for the ability to measure the effects of childhood SES on LOC orientation. While SES accounts for much of the health disparities, race and ethnicity contribute to the complexity of this relationship. The restricted range of race and ethnicity did not take into account their contribution to the relationships examined.

\section{Implications}

Despite its limitations, this study provides novel information about the role of poverty and global perception of control and health behavior that goes beyond the domain specific aspects of HLOC. The use of a generalized control measure was intended to examine the complex relationship between nonhealth-specific worldviews and health behavior. Further, the finding that a MLOC-C orientation presents an increased risk of poor health behavior and psychological distress symptoms as compared to a MLOC-PO orientation, illustrates the differences within the external LOC domains.

This study's findings related to higher HPL for powerful others as compared to chance beliefs present novel information that may be used to support professional practice for health providers and health interventionists. If health care providers are perceived as trusted, powerful others, they may be able to influence change by employing an authoritative approach with closer patient monitoring. Brincks, Feaster, Burns, and Mitrani (2010) found that low-income, minority patients with high MLOC-PO reported higher levels of medical provider trust than low-income minority patients with higher MLOC-C orientation. Further, MLOC-PO was also found to be associated with higher rates of adherence to immunization and breast cancer screening recommendations due to increased provider trust among patients with MLOC-PO orientation (Aharon et al., 2018). Bennet et al. (2017) found that high internal and powerful others HLOC predicted willingness to use digital health interventions including mobile health and health behavior tracking tools. The authors infer that the willingness to use digital health technologies for persons with a high MLOC-PO orientation was based on their perception of the provider as a powerful other. For patients with high MLOC-PO orientation, closer monitoring and coaching from medical professionals may elicit healthy behavior change. However, there are few studies that examine the subdomains within externality to discover associated benefits and risks to health (Aharon et al., 2018; Bennet et al., 2017; Brincks et al., 2010). Therefore, this study adds to the scant literature on the dimensions within externality as they relate to health behavior.

Incentive-based health interventions may also increase healthy behavior while addressing the psychosocial factors associated with poverty, such as lack of resources, and a lack of environmental contingency. Conditional cash programs have successfully increased use of preventative health services and health behaviors (Ranganathan \& Lagarde, 2012; Volpp, Troxel, \& Pauly, 2009). Haff et al. (2015) conducted a meta-analysis of several financial incentive based health behavior interventions, and reported the success of this strategy with eliciting health behavior change in areas including smoking cessation, diet, and medication adherence for low-income and minority populations, in particular. 
LOC orientation is considered to be a relatively stable trait, which may explain why few studies have explored methods to shift it (Rotter, 1966). There is an even greater paucity of literature on shifting LOC in low-SES populations. While cognitive interventions and mindfulness training techniques have been successful in shifting LOC from external to internal or increasing perceived control, these techniques have not been studied in low-SES populations (Hamarta, Ozyesil, Deniz, \& Dilmac, 2013; Pagnini, Bercovitz, \& Langer, 2016) Mindfulness training and motivational interviewing may shift control beliefs, while also addressing the mental and spiritual health needs of externals and low-SES populations.

The current study illustrates that chance orientation presents the greatest risk to one's physical and psychological well-being and can be considered a maladaptive response to one's environment or circumstances. Interventions aimed at shifting one's control orientation from chance to powerful others, or powerful others to internal should be studied. Introducing interventions to shift LOC may be more effective for youth, because their worldviews are still in the formative stages (Culpin et al., 2015). Including parents and families may also be beneficial, because they are the primary teachers within the social learning environment. Ahlin and Antunes (2015) discovered that parenting styles including harsh discipline, overprotectiveness, low parental warmth, and lack of supervision greatly predicted an external LOC in childhood along with socioeconomic factors, whereas an internal LOC reduced the likelihood of engaging in violence and other negative behavior, despite environmental exposure to such behavior. Addressing LOC for low-SES youth may mitigate negative consequences associated with poverty.

\section{Future Directions}

As a society, it is our collective responsibility to conduct an honest analysis of the conditions and experiences of our most vulnerable communities and work to improve them. Health psychology and the public health fields have historically worked in separate silos, yet a synergy of these fields could inform new theoretical frameworks and the path to health equity. While study findings serve as a starting point for understanding the factors related to SES, LOC, and health behavior, additional studies are needed to determine how to best address them to achieve health equity. Future studies examining the efficacy and benefits of interventions to shift LOC orientation and the resulting effects on mental and physical health are strongly recommended. LOC screening could assist providers in determining which treatment approach to use. Effective health promotion messages for external LOC should also be studied specifically for chance beliefs, which is associated with the least health promoting behavior, and for which no effective health behavior interventions have been identified. Further solutions to address the unequal distribution of wealth, and opportunities to obtain economic well-being are also needed. Educational achievement, increased employment opportunities, and income enhancements do improve health outcomes, while affording individuals the opportunity to exercise control over where and how they live, work, and engage in recreational activities (Kaplan, Spittel \& David, 2015). Income supplements, such as the U.S. Earned Income Tax Credit for low-income, working families, and increases in Social Security benefit payments resulted in marked improvements in health outcomes for low-income and minority populations (Kaplan et al., 2015).

Social hierarchies and the resulting stratification continue to predict health through myriad factors, including control perceptions. The control beliefs created by SES are pervasive and global, although health beliefs are only one facet of one's overall belief patterns. It is vital to understand LOC as an adaptive response to the disempowered environment created by poverty, as opposed to waiting for a shift in control beliefs that more closely resembles those of the wealthier, dominant culture. A shift needs to occur in the approach to health behavior interventions for low-income populations from agentic models to ones that address the psychological conditions of poverty. 


\section{References}

Adler N. E. (2015). Disadvantage, self-control, and health. Proceedings of the National Academy of Sciences of the United States of America, 112, 10078-10079. doi:10.1073/pnas.1512781112

Aharon, A. A., Nehama, H., Rishpon, S., \& Baron-Epel, O. (2018). A path analysis model suggesting the association between health locus of control and compliance with childhood vaccinations. Human Vaccines \& Immunotherapeutics, 14, 1618-1625, doi:10.1080/21645515.2018.1471305.

Ahlin, E. M., \& Antunes, M. J. (2015). Locus of control orientation: Parents, peers, and place. Journal of Youth and Adolescence, 44, 1803-1818. doi:10.1007/s10964-015-0253-9

Ajzen, I. (1985). From intentions to actions: A theory of planned behavior. In J. Kuhl \& J.Beckman (Eds.), Action-control: From cognition to behavior (pp. 11-39). Berlin, Germany: Springer.

Angelova, N. V. (2016). Locus of control and its relationship with some social-demographic factors. Psychological Thought, 9, 248. doi:10.5964/psyct.v9i2.179

Arcaya, M. C., \& Figueroa, J. F. (2017). Emerging trends could exacerbate health inequities in the United States. Health Affairs (Project Hope), 36, 992-998. doi:10.1377/hlthaff.2017.0011

Bandura, A. (1965). Influence of models' reinforcement contingencies on the acquisition of imitative responses. Journal of Personality and Social Psychology, 1, 589-595.

Baron, R. M., \& Kenny, D. A. (1986). The moderator-mediator variable distinction in social psychological research: Conceptual, strategic and statistical considerations. Journal of Personality and Social Psychology, 51, 1173-1182.

Bennett, B. L., Goldstein, C. M., Gathright, E. C., Hughes. J. W. \& Latner, J. D. (2017). Internal health locus of control predicts willingness to track health behaviors online and with smartphone applications. Psychology, Health, \& Medicine, 229, 1224-1229. doi:10.1080/13548506.2017.1317354

Braveman, P. A., Cubbin, C., Egerter, S., Williams, D. R., \& Pamuk, E. (2010). Socioeconomic Disparities in Health in the United States: What the patterns tell us. American Journal of Public Health, 100, S186-S196. doi:10.2105/AJPH.2009.166082

Brincks, A. M., Feaster, D. J., Burns, M. J., \& Mitrani, V. B. (2010). The influence of health locus of control on the patient-provider relationship. Psychology, Health, \& Medicine, 15, 720-728. doi:10.1080/13548506.2010.498921

Centers for Disease Control and Prevention. (2015). Social determinants of health: Frequently asked questions. Retrieved from http://www.cdc.gov/socialdeterminants/FAQ.html

Chetty, R., Stepner, M., Abraham, S., Lin, S., Scuderi, B., Turner, N., Bergeron, A., Cutler, D. (2016). The association between income and life expectancy in the United States, 2001-2014. Journal of American Medical Association, 315,1750-1766. doi:10.1001/jama.2016.4226

Cobb-Clark, D. A., Kassenboehmer, S. C., \& Schurer, S. (2014). Healthy habits: The connection between diet, exercise, and locus of control. Journal of Economic Behavior \& Organization, 98, 1-28. doi:10.1016/j.jebo.2013.10.011

Cooper, L. A., Purnell, T. S., Showell, N. N., Ibe, C. A., Crews, D. C., Gaskin, D. J., ... Thornton, R. L. J. (2018). Progress on major public health challenges: The importance of equity. Public Health Reports, 133,15S-19S. doi:10.1177/0033354918795164

Culpin, I., Stapinski, L., Miles, Ö. B., Araya, R., \& Joinson, C. (2015). Exposure to socioeconomic adversity in early life and risk of depression at 18 years: The mediating role of locus of control. Journal of Affective Disorders, 183, 269-278. doi:10.1016/j.jad.2015.05.030 
Elliot, A. J., Turiano, N. A., Infurna, F. J., Lachman, M. E., \& Chapman, B. P. (2018). Lifetime trauma, perceived control, and all-cause mortality: Results from the Midlife in the United States Study. Health Psychology, 37, 262-270.

Faul, F., Erdfelder, E., Lang, A. G., \& Buckner, A. (2007). G*Power 3: A flexible statistical power analysis program for the social, behavioral, and biomedical sciences. Behavior Research Methods, 39, 175-191. doi:10.3758/BF03193146

Goldberg, D. S. (2012). Social justice, health inequalities and methodological individualism in U.S. health promotion. Public Health Ethics, 5, 104-115.

Grotz, M., Hapke, U., Lampert, T., \& Baumeister, H. (2011). Health locus of control and health behaviour: Results from a nationally representative survey. Psychology, Health \& Medicine, 16, 129-140. doi:10.1080/13548506.2010.521570

Haff, N., Patel, M. S., Lim, R., Jingsan, Z., Troxel, A. B., Asch, D. A., \& Volpp, K. G. (2015). The role of behavioral economic incentive design and demographic characteristics in financial incentive-based approaches to changing health behaviors: A meta-analysis. American Journal of Health Promotion, 29, 314-323. doi:10.4278/ajhp.140714-LIT- 333

Hamarta, E., Ozyesil, Z., Deniz, M., \& Dilmac, B. (2013). The prediction level of mindfulness and locus of control on subjective well-being. International Journal of Academic Research, 5, 145150. doi:10.7813/2075-4124.2013/5-2/B.22

Havranek, E. P., Mujahid, M. S., Barr, D. A., Blair, I. V., Cohen, M. S., Cruz-Flores, S., ... Yancy, C. W. (2015). Social determinants of risk and outcomes for cardiovascular disease: A scientific statement from the American Heart Association. Circulation, 132, 873-898.

Healthypeople.gov. (2015). Social determinants of health: Healthy People 2020. Retrieved from http://www.healthypeople.gov/2020/topics-objectives/topic/social-determinants-health

Hochbaum, G. M. (1960). Research relating to health education. Health Education Monographs, 1, 10-21. doi:10.1177/109019816000100802.

Holt, C. L., Clark, E. M., Kreuter, M. W., \& Scharff, D. P. (2000). Does locus of control moderate the effects of tailored health education materials? Health Education Research, 15, 393-403.

Kaplan R., Spittel, M., David, D. (2015). Population health: Behavioral and social science insights (Publication No. 15-0002). Rockville, MD: Agency for Healthcare Research and Quality and Office of Behavioral and Social Sciences Research, National Institutes of Health. Retrieved from https://www.ahrq.gov/professionals/education/curriculum-tools/populationhealth/index.html

Kessler, R. C. (2002). Short screening scales to monitor population prevalence and trends in nonspecific psychological distress. Psychological Medicine, 32, 959-956.

Levenson, H. (1974). Multidimensional Locus of Control Scales [Database record]. PsycTESTS. doi:10.1037/t04693-000

Meng, X. I., Rosenthal, R., \& Rubin, D. B. (1992). Comparing correlated correlation coefficients. Psychological Bulletin, 111, 172-175. doi:10.1037/0033-2909.111.1.172

Miller, G. E., Yu, T., Chen, E., \& Brody, G. H. (2015). Self-control forecasts better psychosocial outcomes but faster epigenetic aging in low-SES youth. Proceedings of the National Academy of Sciences of the United States of America, 112, 10325-10330.

Mittal, C., \& Griskevicius, V. (2014). Sense of control under uncertainty depends on people's childhood environment: A life history theory approach. Journal of Personality and Social Psychology,107, 621-637. doi:10.1037/a0037398 
Moy, E., Garcia, M. C., Bastian, B., Rossen, L. M., Ingram, D.D. (2017). Leading causes of death in nonmetropolitan and metropolitan areas: United States, 1999-2014. MMWR Surveillance Summary, 66, 1-8. doi:10.15585/mmwr.ss6601a1

Nettle, D. (2010). Why are there social gradients in preventative health behavior? A perspective from behavioral ecology. PLoS ONE, 5, e13371. doi:10.1371/journal.pone.0013371

Pagnini, F., Bercovitz, K., \& Langer, E. (2016). Perceived control and mindfulness: Implications for clinical practice. Journal of Psychotherapy Integration, 26, 91-102.

Pender, N. J. (1996). Health promotion in nursing practice (3rd ed.). Stamford, CT: Appleton and Lange.

Prochaska, J. O., \& DiClemente, C. C. (1983). Stages and processes of self-change of smoking: Toward an integrative model of change. Journal of Consulting and Clinical Psychology, 51, 390-395.

Proffitt Leyva, R. P., \& Hill, S. E. (2018). Unpredictability, body awareness, and eating in the absence of hunger: A cognitive schemas approach. Health Psychology, 37, 691-699. doi:10.1037/hea0000634

Ranganathan, M., \& Lagarde, M. (2012). Promoting healthy behaviours and improving health outcomes in low and middle income communities: A review of the impact of conditional cash transfer programmes. Preventative Medicine 55, S95-S105. doi:10.1016/j.ypmed.2011.11.015

Rotter, J. B. (1966). Generalized expectancies for internal versus external control of reinforcement. Psychological Monographs: General and Applied, 80, 1-28. doi:10.1037/h0092976

Seligman, M.E., \& Maier, S.F. (1967). Failure to escape traumatic shock. Journal of Experimental Psychology 74, 1-9. doi:10.1037/h0024514

Sheffer, C., MacKillop, J., McGeary, J., Landes, R., Carter, L., Yi, R., ... Bickel, W. (2012). Delay discounting, locus of control, and cognitive impulsiveness independently predict tobacco dependence treatment outcomes in a highly dependent, lower socioeconomic group of smokers. American Journal on Addictions, 21, 221-232. doi:10.1111/j.15210391.2012.00224.x

Turiano, N. A., Silva, N. M., McDonald, C., \& Hill, P. L. (2017). Retrospective reports of childhood misfortune are associated with positive and negative affect in adulthood: Exploring the moderating role of control beliefs. The International Journal of Aging \& Human Development, 84, 276-293. doi:10.1177/0091415016688480

U.S. Department of Health and Human Services. (2017). 2017 Poverty guidelines. Retrieved from https://aspe.hhs.gov/2017-poverty-guidelines

Volpp, K. G., Troxel, A. B., Pauly, M. V. (2009). A Randomized controlled trial of financial incentives for smoking cessation. New England Journal of Medicine 360, 355-367.

Walker, S., Sechrist, K., \& Pender, N. (1995). The Health-Promoting Lifestyle Profile II. Omaha, NE: University of Nebraska Medical Center, College of Nursing. Retrieved from http://hdl.handle.net/10477/2957

Wallston K. A., Wallston B. S., \& DeVellis R. (1978). Development of the Multidimensional Health Locus of Control (MHLC) scales. Health Education \& Behavior, 6, 160-170. 
The Journal of Social, Behavioral, and Health Sciences is an open-access, peer-reviewed, online interdisciplinary journal focusing on research findings that address contemporary national and international issues. Its objectives are to (a) encourage dialogue between scholars and practitioners in the social, behavioral, and health sciences that fosters the integration of research with practice; (b) promote innovative models of interdisciplinary collaboration among the social, behavioral, and health sciences that address complex social problems; and (c) inform the relationship between practice and research in the social, behavioral, and health sciences.

Walden University Publishing: http://www.publishing.waldenu.edu 